\title{
Tension pneumopericardium and pneumothorax during spontaneous ventilation
}

\author{
Francesco Petteruti, MD, ${ }^{\text {a }}$ Paolo Stassano, MD, ${ }^{\mathrm{b}}$ Giuseppe De Luca, MD, ${ }^{a}$ Luigi Di Tommaso, MD, ${ }^{\mathrm{b}}$
} Antonella Luciano, MD, ${ }^{a}$ and Paolo Pepino, MD, ${ }^{a}$ Naples, Italy

$\mathrm{P}$

neumopericardium is a complication of blunt or penetrating injuries of the chest, and it usually does not cause hemodynamic compromise. Tension pneumopericardium is less common and may indeed be life-threatening. It usually occurs in patients receiving assisted ventilation. ${ }^{1,2} \mathrm{We}$ report a case of tension pneumopericardium in a patient during spontaneous ventilation.

\section{Clinical Summary}

A 45-year-old man was involved in a high-speed motor vehicle crash. A prolonged extrication was required and the initial evaluation at the scene revealed fractures of the ribs, right arm, and left femur as well as cranial trauma without neurologic deficit. He was in stable condition and did not require mechanical ventilation. On admission to the hospital, the patient was in respiratory distress, agitated, and had chest and abdominal pain. Oxygen saturation was $90 \%$ on $50 \%$ oxygen delivered by face mask, systolic blood pressure $90 \mathrm{~mm} \mathrm{Hg}$, heart rate 130 beats/min, and hemoglobin level $12.8 \mathrm{~g} / \mathrm{dL}$. Physical examination revealed a large subcutaneous thoracic emphysema with asymmetry of the chest, and the pulmonary sounds were absent. The clinical picture was compatible with tension left pneumothorax. A chest tube was inserted and a bolus of fluid was given. The oxygen saturation improved, but the patient remained tachycardic (130 beats/min) and hypotensive (systolic blood pressure $85 \mathrm{~mm} \mathrm{Hg}$ ), and neck vein distention and pulsus paradoxus appeared. A total-body computed tomographic (CT) scan revealed-besides rib, left femur, and right humerus fractures - a large tension pneumopericardium, left hemopneumothorax, and bilateral lung contusions (Figure 1, A). A second chest tube was inserted and forceful aspiration was applied. With suction, the patient's clinical condition improved, neck vein distention disappeared, and blood pressure normalized. The tension pneumopericardium disappeared (Figure 1, B). Examination with a fiberoptic bronchoscope excluded tracheobronchial lesions. Chest tubes were left in suction and were removed on the seventh and eighth days, respectively. The patient was discharged 1 month later and

From the Cardiothoracic Surgery Department, Clinica Pineta Grande Castelvolturno (CE), ${ }^{\mathrm{a}}$ and the Cardiac Surgery Department, University

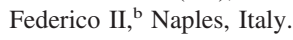

Received for publication Sept 17, 2006; accepted for publication Nov 8, 2006.

Address for reprints, Francesco Petteruti, MD, Via Lauria 38, 81100 Caserta, Italy (E-mail: tea41273@ @libero.it).

J Thorac Cardiovasc Surg 2007;133:829-30

0022-5223/ $\$ 32.00$

Copyright $\odot 2007$ by The American Association for Thoracic Surgery doi:10.1016/j.jtcvs.2006.11.008 was sent to a rehabilitation center (Figure 1,C). Three months later the patient is in good condition (Figure 2).

\section{Discussion}

The mere presence of air in the pericardium may not be responsible for hemodynamic derangement, but sometimes it can cause a frightening complication: tension pneumopericardium. Tension pneumopericardium occurs most often in patients requiring mechanical ventilation as a result of penetrating injures of the chest or
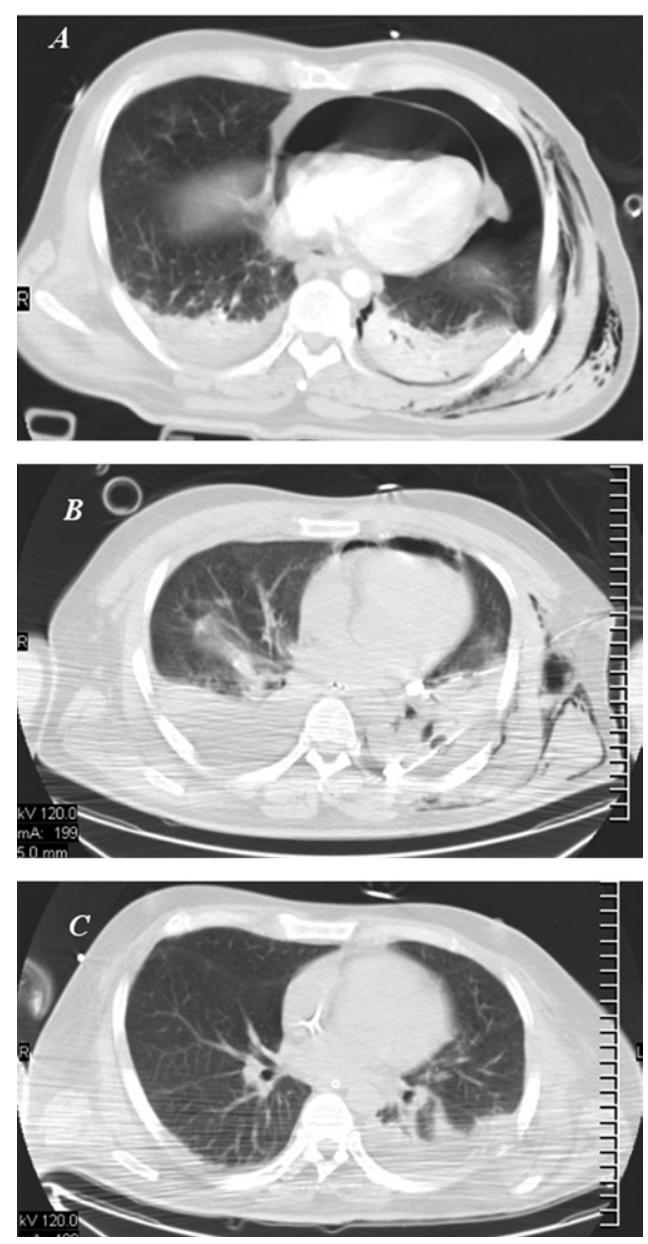

Figure 1. A, Chest CT scan shows tension pneumopericardium with flattening of the anterior border of the heart. B, With forceful aspiration, almost complete resolution of the tension pneumopericardium is achieved. A small amount of air is still present, without causing hemodynamic compromise. C, CT scan at the patient's dismissal 1 month later. 


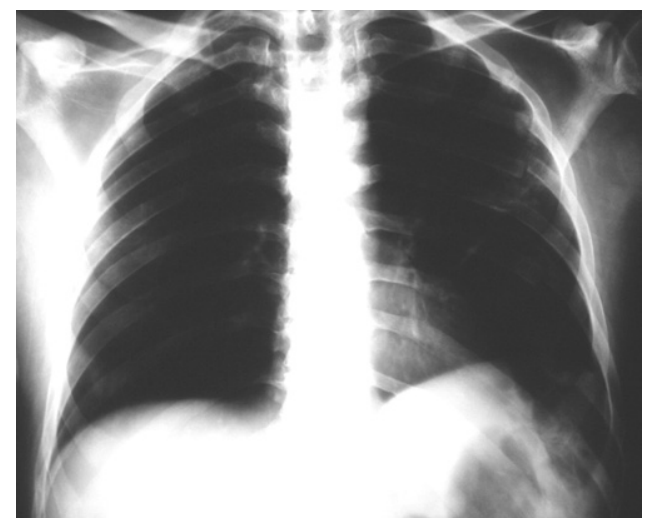

Figure 2. Chest radiography 3 months later.

blunt chest trauma. ${ }^{3,4}$ Rarely does it develop in patients who are spontaneously breathing. ${ }^{2}$ Mortality resulting from tension pneumopericardium can exceed $50 \% .^{1}$ Therefore, an early diagnosis and immediate treatment are crucial for the patient's life.

After thoracic trauma, air can enter the pericardial sac in one of several routes. ${ }^{3}$ A sudden increase in intra-alveolar pressure may rupture some of the alveoli and, if there is also a laceration in the pericardium, air can enter the pericardial sac. The pericardial tissue may work as a valve, letting air in and not out into the chest. Moreover, from ruptured alveoli the air can travel along the peribronchial sheaths and go into the pericardium. Macklin ${ }^{5}$ demonstrated that air can travel from the pleura into the pericardial sac because of a discontinuity in the pericardial tissue at the reflection of parietal onto visceral pleura close to the pulmonary veins. Another possible mechanism for the development of pneumopericardium can be a traumatic direct connection between the bronchial tree and the pericardial sac.

A high index of suspicion is necessary to diagnose tension pneumopericardium because hemodynamic collapse may initially be ascribed to the trauma (in case of blunt trauma) or to hemorrhage (in case of penetrating injury). The described mill-wheel murmur may be masked, as in our patient, by subcutaneous emphysema.
Chest radiography may not disclose abnormalities. ${ }^{2}$ Chest CT scan is of paramount importance in the diagnosis of tension pneumopericardium. In fact, CT scan findings of pericardial tamponade are present even when the clinical diagnosis is uncertain. CT scan shows air in the pericardial space and the flattening of the anterior border of the heart with a decrease in the anteroposterior diameter. ${ }^{6}$ Examination with a fiberoptic bronchoscope is important to ascertain tracheobronchial lesions.

Tension pneumopericardium requires emergency surgical treatment through a thoracotomy or subxiphoid incisions or through a thoracoscopic access. Echo-guided pericardiocentesis and placement of percutaneous drains may be attempted but may yield unsatisfactory results. ${ }^{3,7}$ Conservative treatment has also been reported. $^{2}$

In our patient, the absence of a tracheobronchial lesion, the absence of heart herniation, and the presence of other severe lesions suggested a more conservative approach with chest tube insertion and aspiration.

In conclusion, because tension pneumopericardium may be a lethal condition, a high index of suspicion is mandatory for its diagnosis. Under certain conditions, tension pneumopericardium can be resolved with conservative treatment.

\section{References}

1. Fulda G, Rodriguez A, Turney SZ, Cowley RA. Blunt traumatic pericardial rupture. A ten-year experience 1979 to 1989. J Cardiovasc Surg (Torino). 1990;31:525-30.

2. Kallel N, Beloeil H, Geoffroy A, Albaldejo P, Marty J. Pneumothorax et pneumopéricarde compressifs post-traumatiques en ventilation spontanée. Ann Fr Anesth Reanim. 2004;23:364-6.

3. Gould JC, Schurr MA. Tension pneumopericardium after blunt chest trauma. Ann Thorac Surg. 2001;72:1728-30.

4. Capizzi PJ, Martin M, Bannon M. Tension pneumopericardium following blunt injury. J Trauma. 1995;39:775-80.

5. Macklin CC. Transport of air along sheaths of pulmonic blood vessels from alveoli to mediastinum: clinical implications. Arch Intern Med. 1939;64:913-26.

6. Hernandez-Luvando L, Calvo J, Gonzales de las Heras E, de la Puente H, Lopez C. Tension pericardial collections: sign of "flattened heart" in CT. Eur J Radiol. 1996;23:250-2.

7. Bronckorst MWGA, Bruijninckx MMM, Ulrich C. Tension pneumopericardium following blunt thoracic trauma and lobectomy. Injury. 2000;31:124-5. 